\title{
Clinical Study of Concomitant Strabismus.
}

\author{
Sachit Mahajan ${ }^{1}$, Satish Kumar Gupta²
}

1. Junior Resident, Upgraded Department of Ophthalmology,Government Medical College, Jammu.

Submission : 24-11-2020

Review : 29-11-2020

Acceptance 2-12-2020

\section{Professor and Head, Department of Ophthalmology, Government Medical College, Jammu.}

Corresponding Author: Dr. Sachit Mahajan Lane No. 2 (Down), Greater Kailash,

Jammu, Jammu and Kashmir, India. 180011. Ph +91-9419238870

Email: mahajansachit1992@gmail.com

DOI: 10.47799/pimr.0803.10

(C) 2020-21 Prathima Institue of Medical Sciences

\section{Abstract}

Background and Objectives: Strabismus is a condition in which there is misalignment of visual axes of two eyes. Concomitant strabismus is a condition in which the angle of deviation is constant in all the directions of gaze. Concomitant strabismus is further classified as convergent, divergent, hyperdeviation and hypodeviation. Major presenting complaints include cosmetic blemish, diminution of vision, asthenopic symptoms like headache, eye strain and diplopia. This study was conceptualized to study the clinical and ophthalmological profile of patients with concomitant strabismus, in order to generate evidence to manage this condition more effectively.

Material and Methods : This cross-sectional, observational study was conducted over a period of two years in 120 patients with concomitant strabismus. Ocular history and visual acuity were recorded. Cover, cover-uncover, alternate cover test, Hirschberg test, Krimsky test and examination by synaptophore were done. Refraction and fundus examination was also done.

Result: Majority of the patients were under 5 years of age $(46.6 \%)$ with male to female ratio of $2: 3$. Convergent squint was more common (71.6\%) with majority of patients having moderate degree of deviation (58.8\%). Hypermteropia was more commonly associated with squint (65\%) more so with convergent squint. Eccentric fixation was present in only $10 \%$ of the cases.

Conclusion: Convergent concomitant squint is more common type with majority of patients having moderate degree of deviation. Hypermetropia is more commonly associated with concomitant squint. Appropriate refraction and timely intervention can help in preventing amblyopia in young children.

Keywords: Strabismus, Hyperopia, Myopia, Esotropia, Exotropia.

\section{Background and Objectives}

The word strabismus in classical Greece means "to squint, to turn". Under normal conditions the nervous system and the extra-ocular muscles work together to keep the eyes aligned by depth perception and movement of both the eyes to bring the object of attention on to the fovea respectively, thereby enabling binocular single vision. ${ }^{1}$ Strabismus is a condition in which there is misalignment of visual axes of two eyes, so that the image of object of regard falls on fovea of one eye (fixing eye) and on the extra foveal area of the other eye (called as the deviating eye). ${ }^{2}$ Concomitant strabismus is a condition in which the angle of deviation is constant in all the directions of gaze. In concomitant strabismus there is a defect in either afferent pathway, due to poor visual acuity or the central mechanism mediating fixation and fusion is underdeveloped or has broken down. This breakdown may be due to excessive convergence required with accommodation in hypermetropes. It accounts for $95 \%$ of all the cases of strabismus. Concomitant strabismus is further classified as convergent, divergent, hyperdeviation and hypodeviation depending on the direction of deviation of the eye. It can also be classified as constant or intermittent, depending on the consistency of the deviation. It can be uniocular or alternating depending upon the type of fixation. ${ }^{3}$

Esotropia or convergent squint can further be classified as accommodative, non-accomodative and partially accommodative. In case of non-accomodative esodeviation, angle of deviation remains same at both near and distance fixation. Accomodative esotropia, can further be classified as refractive, non-refractive and mixed depening upon the refractive error and $A C / A$ ratio. Refractive accommodative esotropia is fully corrected with hypermetropic correction for distance, whereas non-refractive accommodative esotropia requires additional hypermetropic correction for near work. Partially accommodative esotropia is partly corrected by refractive correction. ${ }^{3}$

Exotropia or divergent squint can be intermittent or constant. It is more common in myopes. Patients with concomitant strabismus are usually asymptomatic. Major presenting complaints include cosmetic disfigurement, diminution of vision, asthenopic symptoms like headache, eye strain and diplopia, which may be present in initial stages only and disappears due to suppression. This prolonged suppression of image in the squinting eye may lead to amblyopia. Suppression affects the fovea and visual acuity becomes greater at some eccentric point on retina, leading to abnormal retinal correspondence and eccentric fixation. ${ }^{3}$ 
This study was conceptualized to study the clinical and ophthalmological profile of patients with concomitant strabismus, in order to generate evidence to manage this condition more effectively.

\section{Material and Methods}

This cross-sectional, observational study was conducted over a period of two years from March 2018 to March 2020 in the Ophthalmology department of a tertiary care teaching hospital in North India, after taking permission from institutional ethics committee.

Patients who fulfilled the following criteria were included in the study and a written informed consent was taken from all the study participants after explaining the purpose of the study.

\section{Inclusion Criteria:}

Patients of all the age groups and of either gender.

Exclusion criteria:

1. Consecutive strabismus

2. Patients with paralytic strabismus.

3. Patients with central nervous system abnormalities.

4. Patients that have undergone previous surgery with residual deviations

5. Cases with palpebral fissure abnormalities.

This study included 120 patients who were subjected to detailed history taking regarding their complaints and ocular examination. Distance visual acuity was recorded with Snellen visual acuity chart, illiterate $E$ test, Landolt test types and picture card test, depending upon the age of the patient. Ocular movements were recorded uniocularly and binocularly. The diagnosis of concomitant squint was made on the basis of cover test, uncover test and alternate cover test.

Angle of deviation was measured using Hirschberg test, Krimsky test, prism and alternate cover test and with synaptophore. In addition to this, Worth four dot test, fixation and fundus were also evaluated.

All the data was entered in Microsoft Excel and subsequently expressed as percentages and proportions. The quantitative variables were expressed as mean $( \pm S D)$. The data was analyzed using OpenEpi online software version 3.

\section{Results}

Socio-demographic characteristics of patients with concomitant squint is shown in table 1.

As evident from table 2, majority of the patients presenting with complaints of deviation of the eye and diminution of vision (58.3\%), followed by complaint of deviation of eye alone (33.3\%).

Characteristics of concomitant squint is shown in table 3. There were more cases of covergent squint or esotropia (71.6\%) as compared to divergent squint or exotropia (28.4\%).
Involvement of eye is shown in figure 1.

The type of refractive error associated with squint is shown in figure 2. Hypermetropia was present in $65 \%$ cases of concomitant squint followed by myopia (20\%).

The amount and distribution of refractive error with squint is shown in table 4. Hypermetropia is more commonly associated with convergent squint with average refraction of $+2.50 \mathrm{D}$ (+0.50D to +8.00D). Hypermetropia and myopia were equally distributed in divergent squint with average refraction of $+1.46 \mathrm{D}(+0.50 \mathrm{D}$ to $+2.00 \mathrm{D})$ and $-1.64 \mathrm{D}(-0.50 \mathrm{D}$ to $2.5 \mathrm{D})$ respectively.

The fixation pattern in concomitant squint is shown in table 5 . Majority of the patients (33.3\%) had foveal fixation. Patients with peripheral or eccentric fixation (10\%) have more chances of developing amblyopia.

Table 1: Socio-demographic profile of patients with concomitant squint

\begin{tabular}{|c|c|c|}
\hline Age ( in years) & $\mathbf{n}$ & percentage \\
\hline $0-5$ & 56 & $46.6 \%$ \\
\hline $6-10$ & 26 & $21.6 \%$ \\
\hline $11-15$ & 20 & $16.6 \%$ \\
\hline $16-20$ & 10 & $8.3 \%$ \\
\hline$>21$ & 8 & $6.6 \%$ \\
\hline Gender & $\mathbf{n}$ & Percentage \\
\hline Males & 48 & $40 \%$ \\
\hline Females & 72 & $60 \%$ \\
\hline Occupation & $\mathbf{n}$ & Percentage \\
\hline Pre-school Children & 48 & $40 \%$ \\
\hline School going children & 62 & $51.6 \%$ \\
\hline College students & 08 & $6.6 \%$ \\
\hline Unemployed & 02 & $1.6 \%$ \\
\hline Total & 120 & $100 \%$ \\
\hline
\end{tabular}

Table 2 : Presenting complaints in case of concomitant squint

\begin{tabular}{|c|c|c|}
\hline Presenting Complaint & $\mathbf{n}$ & percentage \\
\hline Deviation of the eye & 40 & $33.3 \%$ \\
\hline $\begin{array}{c}\text { Deviation of the eye with } \\
\text { diminution of vision }\end{array}$ & 70 & $58.3 \%$ \\
\hline $\begin{array}{c}\text { Deviation of the eye with } \\
\text { headache }\end{array}$ & 10 & $8.3 \%$ \\
\hline
\end{tabular}


Table 3 : Characteristics of concomitant squint

\begin{tabular}{|c|c|c|c|}
\hline Age ( in years) & $\begin{array}{c}\text { Number of } \\
\text { cases }\end{array}$ & $\begin{array}{c}\text { Convergent } \\
\text { squint }\end{array}$ & $\begin{array}{l}\text { Divergent } \\
\text { Squint }\end{array}$ \\
\hline $0-2$ & 68 & 48 & 20 \\
\hline $2-4$ & 24 & 20 & 04 \\
\hline $4-6$ & 10 & 06 & 04 \\
\hline $6-8$ & 10 & 08 & 02 \\
\hline 8-10 and above & 08 & 04 & 04 \\
\hline Total & 120 & $86(71.6 \%)$ & $34(28.4 \%)$ \\
\hline Angle of deviation & Number of cases & Convergent Squint & Divergent squint \\
\hline <15 Degree & $38(31.6 \%)$ & $30(34.8 \%)$ & $8(23.5 \%)$ \\
\hline $15-25$ degree & 72 (60\%) & $52(60.45 \%)$ & 20 (58.8\%) \\
\hline$>25$ degree & $10(8.3 \%)$ & $4(4.65 \%)$ & $6(17.6 \%)$ \\
\hline Visual Acuity & Number of patients & Convergent Squint & Divergent Squint \\
\hline $6 / 6$ & 36 & 28 & 08 \\
\hline $6 / 9$ & 20 & 16 & 04 \\
\hline $6 / 12$ & 18 & 10 & 08 \\
\hline $6 / 18$ & 14 & 08 & 06 \\
\hline $6 / 24$ & 14 & 08 & 06 \\
\hline $6 / 36$ & 06 & 06 & 00 \\
\hline $6 / 60$ & 08 & 06 & 02 \\
\hline$<6 / 60$ & 04 & 04 & 00 \\
\hline
\end{tabular}

Figure 1: Involvement of the eye in squint. Involvement of the eye

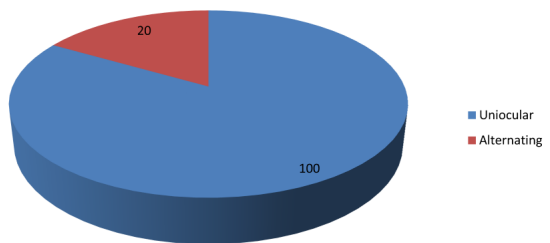

Figure 2: Refractive error associated with squint.

Refractive error associated with squint

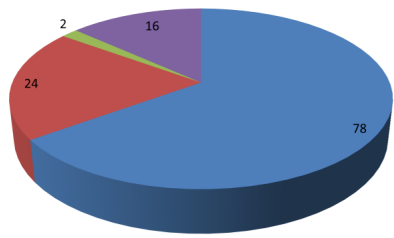

- Myopia

- Anisometropia

- Emmetropia
Table 4 : The amount and distribution of refractive error with squint

\begin{tabular}{|c|c|c|c|c|}
\hline & $\begin{array}{l}\text { Hyper- } \\
\text { metropia }\end{array}$ & Myopia & $\begin{array}{c}\text { Anisom- } \\
\text { etropia }\end{array}$ & $\begin{array}{l}\text { Emme- } \\
\text { tropia }\end{array}$ \\
\hline $\begin{array}{c}\text { Convergent } \\
\text { squint }\end{array}$ & $\begin{array}{l}64 \\
+2.50 \mathrm{D} \text {, range: } \\
+0.5 \mathrm{D} \text { to }+8.00 \mathrm{D}\end{array}$ & $\begin{array}{l}10 \\
-2.50 \text { D. range: } \\
-0.50 D \text { to - } \\
4.00 D\end{array}$ & 02 & 10 \\
\hline $\begin{array}{c}\text { Divergent } \\
\text { Squint }\end{array}$ & $\begin{array}{l}14 \\
+1.46 \mathrm{D} \text {, range: } \\
+0.50 \mathrm{D} \text { to } \\
+2.00 \mathrm{D}\end{array}$ & $\begin{array}{l}14 \\
-1.64 \mathrm{D} \text {, range } \\
-0.50 \mathrm{D} \text { to } 2.5 \mathrm{D}\end{array}$ & 0 & 06 \\
\hline
\end{tabular}

Distribution of refractive error in convergent Squint

\begin{tabular}{|l|l|l|l|l|}
\hline $\begin{array}{l}\text { Type of } \\
\text { squint }\end{array}$ & $\begin{array}{c}\text { No. of } \\
\text { cases }\end{array}$ & $\begin{array}{c}\text { Mean refractive } \\
\text { error }\end{array}$ & $\begin{array}{l}\text { Standard } \\
\text { Deviation }\end{array}$ & Range \\
\hline $\begin{array}{l}\text { Fully } \\
\text { accommodative }\end{array}$ & 18 & $+4.72 \mathrm{D}$ & $\pm 1.96 \mathrm{D}$ & $\begin{array}{l}+2.50 \mathrm{D} \text { to } \\
+8.00 \mathrm{D}\end{array}$ \\
\hline $\begin{array}{l}\text { Partially } \\
\text { Accommodative }\end{array}$ & 38 & $+1.89 \mathrm{D}$ & $\pm 1.01 \mathrm{D}$ & $\begin{array}{l}+1.00 \mathrm{D} \text { to } \\
+5.00 \mathrm{D}\end{array}$ \\
\hline $\begin{array}{l}\text { Non- } \\
\text { Accommodative }\end{array}$ & 30 & $-0.85 \mathrm{D}$ & $\pm 2.01 \mathrm{D}$ & $\begin{array}{l}-4.00 \mathrm{D} \text { to } \\
+1.50 \mathrm{D}\end{array}$ \\
\hline
\end{tabular}

Table 5: Fixation pattern in concomitant squint

\begin{tabular}{|l|l|l|}
\hline \multicolumn{1}{|c|}{ Type of fixation } & \multicolumn{1}{c|}{$\mathbf{n}$} & \multicolumn{1}{c|}{ percentage } \\
\hline Foveal & 40 & $33.3 \%$ \\
\hline Parafoveal & 38 & $31.6 \%$ \\
\hline Paramacular & 30 & $25 \%$ \\
\hline Peripheral & 12 & $10 \%$ \\
\hline Total & 120 & $100 \%$ \\
\hline
\end{tabular}

\section{Discussion}

Concomitant squint is the most common type among the manifest squints. Our study aims to correlate various known facts about the concomitant squint. Out of 120 patients in our study, 72 patients (60\%) were females and 48 (40\%) were male. Tubing $\mathrm{K}$ et al. in their study reported $55.16 \%$ females. 4 Dalia $S$ et al also reported that comitant squint was more common in females. ${ }^{5}$ Higher incidence in females could be due to cosmetic blemish among the females.

Maximum cases of concomitant squint (46.6\%) were present in age group of birth to five years of age. Tubing $\mathrm{K}$ et al reported maximum incidence in age of 7-12 years, ${ }^{4}$ whereas Sarosh et al and Greenberg et al reported that majority of patients in their respective studies were under 10 years of age.6,7.Chopra 
$\mathrm{V}$ also reported $35 \%$ cases in the age group of $0-5$ years and $20 \%$ cases in the age group of 6-10 years. ${ }^{8}$ Children under 10 years of age accounted for maximum number of cases in our study as well (68.2\%). Yu CBO et al, retrospectively analyzed 2704 cases and found the mean age of presentation to be 14.1 years which is higher than our study, ${ }^{9}$ where mean age was 8.42 years. This could be attributed to the parents or some relative noticing asymmetry in the alignment between the two eyes resulting in earlier presentation to the ophthalmologist.

History taking in case of squint is a ticklish problem because the child is too young to talk about the symptoms and parents are sometimes not so observant and sometimes overanxious resulting in information which cannot be relied upon $100 \%$. On the study of relationship between reported associated factors, it was observed that 14 patients had history of febrile illness before the onset of squint, eight patients had history of trauma and two patients suffered from gastroenteritis.

Various genetic factors associated with squint could not be studied as family members were not available for workup. While immediate parents were studied where so ever possible and it was found that eight parents of concomitant cases were suffering from the similar type, while there were none amongst the immediate parents in comitant divergent squint. While considering brothers and sisters, an interesting family with twins who were monozygous with convergent squint were found. There were more cases of covergent squint or esotropia (71.6\%) as compared to divergent squint or exotropia (28.4\%). Datta D, also reported that esotropia (74\%) was more common than exotropia (26\%) in their study. ${ }^{10}$ Chopra $\mathrm{V}$ et al, in their study reported $57 \%$ cases of esotropia and $43 \%$ cases of exotropia. 8 On the other hand, Chia A et al reported higher prevalence of exotropia than esotropia by ratio of $7: 1 .^{11}$

Very large deviation beyond 25 degree were infrequent as these totaled only $8.3 \%$ cases while squints less than 15 degree were more common (31.6\%), thus making squint with moderate deviation 15-25 degree as the single main group (60\%). Similar observation have been made by Sarosh et al, who reported angle of deviation between 20-40 prism diopters as major group. ${ }^{6}$ Chopra $V$ et al also reported maximum cases with angle of deviation between 11-20 degrees. ${ }^{8}$ The reason for least number of patients in group with $>25$ degrees deviation could be general apathy of patients to their disease and lack of interest in the treatment or the patient might have received the treatment before squint could have advanced to such a high degree. As with squint with less than 15 degree, quite a few parents might be missing the presence of squint due to tender age of the child or thinking that it would be alright with the passage of time as is usually told by some medical practioners. As the policy of wait and watch fails, squint remains there and becomes more evident with the increase in age so that the child is brought to the doctor, accounting for most cases falling in category of 15-25 degrees.
Most of the convergent squint cases were related to hypermetropia (60\%) followed by myopia (20\%). Tubing K et al reported that all the cases of squint were associated with refractive error, with hypermetropia being most common (33.3\%) followed by myopia (22.92\%). They also reported that hypermetropia was more commonly associated with convergent squint and myopia with divergent squint. ${ }^{4}$ Chopra $V$ et al, also reported that hypermetropia was associated with maximum cases of squint (54\%). ${ }^{8}$ This is in accordance with our study where hypermetropia was present in 64 out of 86 cases of convergent squint and myopia was present in 14 out of 34 cases of divergent squint.

Visual acuity was most difficult to assess in infants and preschool children due to their age. Rough estimation was made using toys and picture cards in addition to Snellen chart. All the cases of alternate concomitant squint had corrected visual acuity of $6 / 6$ and $6 / 9$. While 36 out of remaining 100 were uniocular and deviation was less than 15 degree., which means that suppression which has started was still in a process of flux and had not become obligatory either due to smaller degree of squint. In the remaining cases, vision tended to be poor in the squinting eye. The delay in timely reporting and intervention can be detrimental to vision.12 From the study it is evident that amblyopia is likely to occur equally in convergent and divergent squint as in uniocular squints, the foveal fixation is replaced by an extrafoveal one, an obligatory suppression resulting in amblyopia.

\section{Conclusions}

We conclude that convergent concomitant squint is more common type with majority of patients having moderate degree of deviation. Hypermetropia is more commonly associated with concomitant squint. Appropriate refraction and timely intervention can help in preventing amblyopia in young children.

\section{Limitations}

Only the patients attending out patient clinics of hospital were included in the study, which may have underestimated the actual problem present in community. Larger scale study in needed to scale the actual problem.

Acknowledgements: Our sincere thanks to all the patients for their support and compliance during this study.

Ethical Approval: Institutional ethics Committee, Government Medical College.

\section{REFERENCES}

1. 1. Singh V, Agarwal S, Singh N, Yadav A. Basics of Understanding Strabismus. In: Strabismus, Agrawal $S$, editor. Springer Nature Publishers, Singapore. 2019; pp 1-17.

2. Elder SD. Ocular motility and strabismus. In: System of Ophthalmology Vol. VI. Elder SD, Wybar K. editors. Mosby publishers, London.1973; Pp223-25. 
3. Sihota R, Tandon R. Comitant Strabismus. In. Parsons Diseases of the Eye. 21st edition. Elsevier Publishers, Navi Mumbai. 2015; Pp: 405-23.

4. Tubing K, Patton T, Usharani L, Basar G, Tsapoe W, Lalhriatpuii ST, et al. Study of Concomitant Strabismus amongstthe EthnicPopulation of Manipur. IOSR-JDMS. 2014. 31(1): 23-28.

5. Dalia S, Anitha S. Concomitant Esotropia- An Analytical Study JMSCR. 2018;6(1):3128-33.

6. Sarosh R, Khan A, Rashid O, Hakak B, Nisa AU, Sarosh P. Profile of strabismus at a tertiary care hospital in Kashmir. Int J Con Med R. 2018;5(6):F4-7.

7. Greenberg AE, Mohney BG, DiehI NN, Bruke JP. Incidence and types of childhood esotropia: a population based study. Ophthalmology. 2007;114(1):170-74.

8. Chopra V, Balasubramanian P, et al. Clinical study of concomitant squint. J. Evid. Based Med. Healthc. 2017; 4(54), 3294-97.

9. Yu CBO, Fan DSP, Wong VWY, Wong CY, Lam DSC. Changing patterns of strabismus: a decade of experience in Hong kong. Br J Ophthalmol 2002;86:854-6.

10. Datta D. Pediatric concomitant strabismus and their relationship with different ametropias. 2011. Available at http//www.independent.academia.edu/html (Accessed September 24, 2020).

11. Chia A, Dirani M, Chan YH, Gazzard G, Au Eong KG, Selvaraj $P$, et al. Prevalence of amblyopia and strabismus in young singaporeanchinese children. Invest Ophthalmol Vis Sci. 2010 Jul;51(7):3411-7.

12. Kikolashvil M, Shengeliia DG, Tsomia LV. Treatment of non accommodated concomitant strabismus. Georgian Med News. 2011 Feb: (191):22-6.

How to cite this article : Mahajan S, Gupta S K. Clinical Study of Concomitant Strabismus. Perspectives in Medical Research 2020; 8 (3):44-48.

DOI: $10.47799 /$ pimr.0803.10

Sources of Support: Nil, Conflict of interest: None declared 